Int. J. Dev. Biol. 53: 805-812 (2009)

doi: $10.1387 /$ ijdb.072499mt

\title{
Generation of pattern and form in the developing limb
}

\author{
MATTHEW TOWERS and CHERYLL TICKLE* \\ Department of Biology and Biochemistry, University of Bath, Bath, UK
}

\begin{abstract}
The developing limb is a major model for pattern formation in vertebrate embryos. Many of the seminal discoveries of the mechanisms involved in patterning have been made using chick embryos because of the ease of manipulating their developing limbs. More recently, the molecular basis of limb pattern formation has been increasingly uncovered and now, with the availability of genomic resources, the genetic approaches available are even more powerful. Nevertheless, since the limb is ultimately built of cells, gene action must ultimately be translated into cell behaviour and a major challenge will be to integrate genetics with molecular and cellular biology. In this review, we will first outline the stages in limb development, the major interacting signalling pathways that pattern the limb and the molecules involved. We will describe fate maps of the developing limb, and discuss what is known about cellular activities including proliferation, death, adhesiveness, communication and migration during the patterning process. Finally we will explore how these cell activities produce form.
\end{abstract}

KEY WORDS: limb, patterning, growth

\section{Outline of limb development and patterning}

The first outward signs of limb development are slight bulges in the body wall at the appropriate levels along the main body axis. These bulges soon become more pronounced and form definite buds, consisting of an apparently homogenous population of undifferentiated mesenchyme cells, mostly derived from the lateral plate mesoderm, encased in ectoderm (Fig. 1A). These buds continue to elongate from the body wall and later begin to take on a limb-like shape with a broad region at the tip of the limb where the digits will form. At the same time as the bud is elongating, mesenchyme cells in the base of the bud, the part nearest the body wall, start to differentiate to lay down the pattern of the specialised tissues of the limb, e.g. the skeleton, while the mesenchyme cells at the tip of the bud remain undifferentiated. The elements of the limb skeleton are laid down in sequence with the structures nearest the main body axis such as humerus/femur of the forelimb/hindlimb forming first, and digits at the tip last (Fig. $1 \mathrm{~B}, \mathrm{C})$.

Cell-cell interactions in the early bud control the development of pattern of limb structures (reviewed, Niswander, 2003). Briefly, there are three main sets of cell-cell interactions in the early limb bud and these control patterning along the three limb axes; antero-posterior (AP; the axis which runs in a human hand from thumb to little finger), proximo-distal (PD; shoulder to finger tips) and dorso-ventral (DV; back of hand to palm, Fig.1A). Signalling by a classical type organizer, the zone of polarizing activity (ZPA) or polarizing region, which comprises a small region of mesenchyme cells at the posterior margin of the limb bud, controls the antero-posterior pattern of the distal part of the limb, in particular the number and pattern of digits (reviewed, Tickle, 2006); the apical ectodermal ridge (AER), the thickening in the ectoderm rimming the limb bud tip is required for bud outgrowth and this is accompanied by the laying down of structures along the proximodistal axis of the limb; while signalling by the ectoderm covering the sides of the bud controls dorso-ventral pattern. Another possible signalling region in the dorso-ventral border of the nonridge ectoderm has been recently discovered in the early limb bud (Nissim et al., 2007) and there is also evidence for local cell-cell interactions between digital rays and interdigital mesenchyme at late stages of development (Dahn and Fallon, 2000).

At least one secreted signalling molecule produced by each of the three main signalling centres has now been identified and will be briefly summarised. The polarizing region produces the diffus-

\footnotetext{
Abbreviations used in this paper: AER, apical ectodermal ridge; AP, anteroposterior; BMP, bone morphogenetic protein; DV, dorso-ventral; FGF, fibroblast growth factor; PD,proximo-distal; Shh, sonic hedgehog; ZPA, zone of polarizing activity.
}

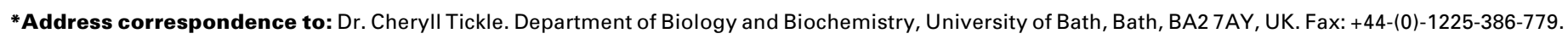
e-mail: cat24@bath.ac.uk

Published online: 3 June 2009.

ISSN: Online 1696-3547, Print 0214-6282

(C) 2009 UBC Press

Printed in Spain 
ible signalling molecule, Sonic hedgehog (Shh) and there is overwhelming evidence that Shh plays a pivotal role in development of the digits (Chiang et al., 1996; Ros et al., 2003). The apical ectodermal ridge expresses genes encoding several different proteins of the Fibroblast Growth Factor family (FGF), in addition to Bone Morphogenetic Proteins (BMPs) and Wnt signalling molecules. It has been shown that FGFs can substitute for the apical ridge and promote limb bud outgrowth and patterning (Niswander etal., 1993; Fallon et al., 1994). Dorsal and ventral ectoderm signalling involves Wnts and Bmps, respectively (reviewed, Niswander, 2003). Expression of genes encoding these signalling molecules is mutually regulated, with a positive feedback loop identified in the chick wing maintaining Shh expression in the polarizing region and Fgf4 expression in the posterior region of the apical ridge; Wnt7a signalling by dorsal ectoderm also helps to maintain Shh expression in the polarizing region (reviewed, Niswander, 2003).

Although the outline above describes key signalling molecules that have been shown to be involved in patterning the three axes of the limb, it should be noted that genes encoding many other secreted signalling molecules are expressed in the limb, for example, Insulin-like Growth Factor (IGF), Platelet-Derived Growth Factor (PDGF) etc, and that diffusible signalling molecules, such as retinoic acid, have also been shown to contribute to generating pattern (Tickle et al., 1982). In addition there are many layers of control that affect both range and strength of signalling including post-translational modification of the signalling molecules themselves, expression of extracellular antagonists and of intracellular molecules that influence signal transduction. Finally, genes that encode molecules involved in direct cell-cell signalling such as the Notch/Delta system (Vargesson et al., 1998), and Ephrins/Ephrin receptors (Araujo et al., 1998) are expressed in the developing limb and these interactions may fine-tune the pattern and/or govern local cell behaviour.

Several genes encoding transcription factors have been identified that are expressed in specific domains in the developing limb in response to signalling along antero-posterior, proximo-distal and dorso-ventral axes. These include the 5' genes of the Hox $A$ and $D$ clusters, $L I M, T b x$, Sall and Shox genes. Functional inactivation of these genes in mice and/or mutations of these genes in human patients, such as in SHOX (Blaschke and Rappold, 2006), lead to limb defects consistent with these genes having a role in the generation of pattern. However, rather little is known about the gene targets of these transcription factors and it is often unclear what cellular activities are primarily affected and lead to these defects.

\section{Activities of cells in the developing limb}

\section{Proliferation}

A number of studies have attempted to map cell proliferation patterns in developing chick and mouse limbs. Some of the earliest work in the chick relied on counting mitotic indices to analyse distribution of proliferation or labelling replicating DNA with tritiated thymidine to calculate cell cycle times or with BrdU

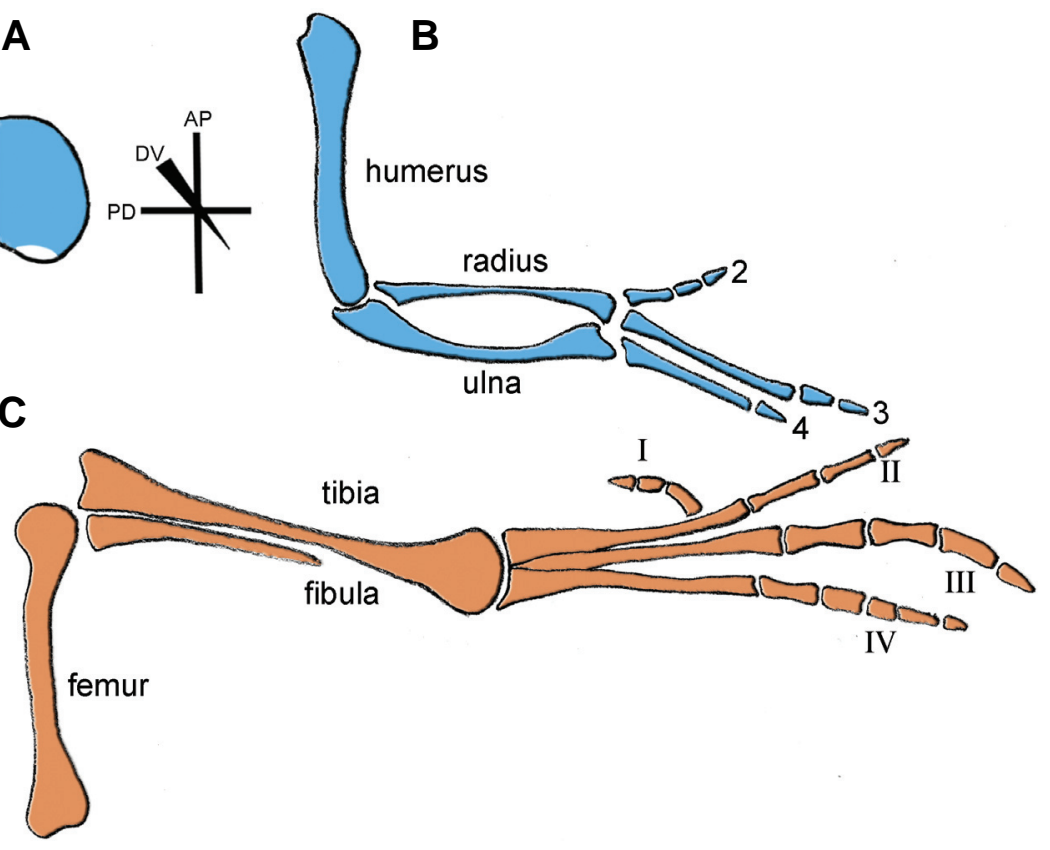

Fig. 1. Chick wing and leg pattern. (A) Early stage chick limb bud (stage 21; 4 days of development) with major axes depicted: antero-posterior (AP), proximo-distal (PD) . Note that the shape of the limb bud is the same at this stage for both the wing and leg. B) Chick wing and (C) chick leg at 10 days of development showing the fully developed skeletal patterns. Note, wrist and ankle elements not shown.

to measure rate of progression through S-phase. During early limb bud stages in the chick, mitotic cells were found to be evenly distributed throughout and cell cycle rates are higher compared to later stages when the bud has grown out proximo-distally (Summerbell and Wolpert, 1972).

The pattern of proliferation changes as cells leave the zone of undifferentiated cells at the tip of the limb bud and differentiate into cartilage in the core of the proximal region of the bud, thus leaving a horseshoe-like distribution of mitotic cells around the periphery of the bud. Recently, Ros and co-workers (Fernandez-Teran et al., 2006) presented a comprehensive analysis of patterns of cell proliferation in sections of both chick and mouse limbs using phospho-Histone H3 labelling of mitotic cells. This confirmed that dividing cells appear to be evenly distributed throughout the early bud and that the number of dividing cells is reduced in regions where cartilage differentiates. In addition they showed that mitotic patterns are similar between the two species at equivalent stages.

\section{Apoptosis}

The spatial distribution of programmed cell death/apoptosis is readily visualised in developing limbs using histochemical stains that label lysed cells and, more recently, TUNEL-labelling which specifically recognises cleaved DNA. The developing limb was one of the classical systems in which programmed cell death was discovered and its most spectacular role in eliminating interdigital webbing in some species including chicks (reviewed, ZuzarteLuis and Hurle, 2002). In early limb buds, several well-defined regions of apoptosis occur, most notably in the chick wing bud, the anterior and posterior necrotic zones (Saunders and Gasseling, 1962). Originally, these areas of the limb were deemed necrotic 
although now it is known that the cells do indeed undergo apoptosis. However, there are species-specific variations in apoptotic patterns as mice do not have a posterior necrotic zone in the early limb bud (Fernandez-Teran et al., 2006) and frogs (Xenopus) form digits without any apparent participation of apoptosis (Cameron and Fallon, 1977). Another region of apoptosis that has been well described in the developing chick wing is the opaque patch which appears in the area where cell proliferation rates fall in the core of the mesenchyme and which comes to lie between the developing radius and ulna (Dawd and Hinchliffe, 1971).

\section{Adhesiveness, cell shape and polarity}

The undifferentiated mesenchymal cells of the early limb bud and at the tip of later buds form a loose meshwork (Fig. 2). One of the major extracellular matrix components between the cells in this meshwork is hyaluronic acid (Toole et al., 1989). Interestingly, when limb bud mesenchyme cells are disaggregated, then cultured and/or reaggregated and grafted back into limb, this meshwork is re-established (Tickle et al., 1978). Each mesenchyme cell has many processes with which they make contact with their neighbours. Junctions found at these contacts include gap junctions made up of connexins 32 and 43 (Makarenkova et al., 1997; Meyer et al., 1997) which allow the direct passage of small molecules from cell to cell. There is evidence that signalling through gap junctions contributes to AP patterning of the limb (Allen et al., 1990) and that expression of gap junction proteins between mesenchyme cells depends on FGF signalling by the apical ectodermal ridge (Green et al., 1994; Makarenkova et al., 1997).

Work on blastemas of regenerating amphibian limbs suggests that cell adhesiveness is graded along the proximal-distal axis of the limb. This was shown, for example, by the spreading behaviour of co-cultured blastemal fragments (Nardi and Stocum, 1984) and by the localisation of cells transfected by a cell-surface molecule (Echeverri and Tanaka, 2005). These differences in adhesiveness appear to be a consequence of proximo-distal positional values. The positional value of cells in an amphibian limb regeneration blastema can be manipulated by retinoic acid (Maden, 1982) and retinoic acid treatment proximalises the positional values of the blastema leading to an alteration in adhesiveness (Brockes, 1992). In the developing chick limb bud, retinoic acid treatment does not lead to gross changes in proximo-distal pattern (Mercader et al., 2000) but grafts of retinoic acid treated mesenchyme cells give rise to more proximal structures than expected (Tamura et al., 1997). Other work by Ide and colleagues has provided further evidence for differential adhesiveness of mesenchyme cells by demonstrating that cells from different proximo-distal levels of chick limb buds sort out in culture (Wada and Ide, 1994); see also recent live imaging of this process (Barna and Niswander, 2007).

It is not clear whether the shape of the mesenchymal cells in the limb bud plays any role in contributing to form at a higher level although this is certainly the case in the apical ectodermal ridge (see below). It should be noted that in the early limb bud, where cells have a higher mitotic rate, the cells are much smaller than those in later stage limb buds which have a lower mitotic rate
(Summerbell and Wolpert, 1972).

Cellular polarity influences properties such as the orientation of the division plane, potentially leading to directional growth, migration and secretion. A number of painstaking studies have monitored the position of the Golgi apparatus as an indicator of polarity of the mesenchyme cells of the limb in particular with respect to the formation of cartilage. These analyses suggested that cell orientation is an early event in the formation of chondrogenic condensations (Trelstad, 1977; Ede, 1977).

\section{Migration}

There is little evidence of extensive movement and/or long distance migration of mesenchyme cells in the early limb bud, although it should be noted that presumptive myogenic cells originate in the dermamyotome of the somites adjacent to the limb-forming regions and delaminate into the lateral plate mesoderm. Grafts of marked limb bud cells in a host chick limb remain coherent (see, for example, (Tickle et al., 1978). In addition, fate mapping experiments in the early chick wing bud (see later) also show that the majority of cells labelled as a small group in the distal part of the limb tend to remain associated and give rise to well-defined stripes at early stages rather than dispersing and intermingling with non-labelled cells (Vargesson et al., 1997).

There is some evidence that apical ridge signals ensure that the presumptive myogenic cells populate the distal parts of the limb bud (Gumpel-Pinot et al., 1984). Mesenchyme cells of the limb bud may be generally responsive to signals from the apical ridge. It was found in experiments in which the apical ridge was removed and replaced by an FGF4 soaked-bead at the posterior edge of the tip, that small groups of labelled cells proximal to the bead expanded distally (Kostakopoulou et al., 1997) and the results of more extensive experiments implanting FGF4-soaked beads led to the suggestion that FGF4 might act as a chemoattractant to limb bud cells (Li and Muneoka, 1999). Interestingly, in early chick embryos, FGFs appear to provide signals that guide cell migration during gastrulation; with FGF4 being a chemoattractant and FGF8 a chemorepellent (Yang et al., 2002).

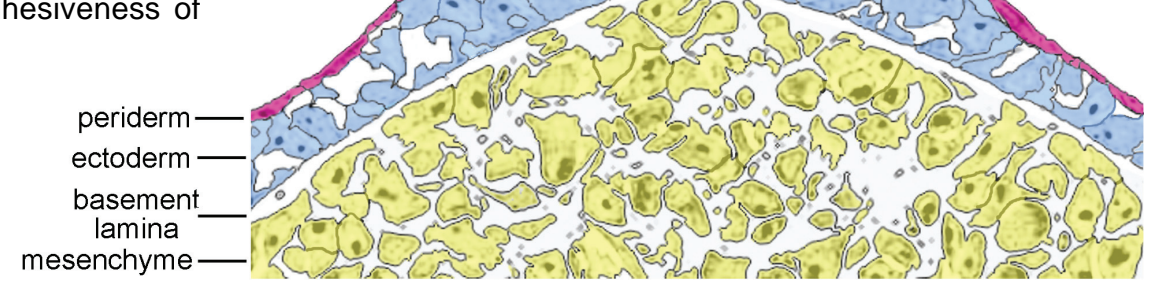

Fig. 2. Structure of the apical ectodermal ridge of the chick wing bud. The shape of the ectodermal cells becomes less cuboidal and is elongated in the apical ectodermal ridge, whereas the overlying periderm is composed of flattened cells in a continuous layer. Also note the presence of intercellular spaces in the ectoderm away from the apex; also in the underlying mesenchyme, which forms a meshwork of cells. Adapted from Todt and Fallon (1986) 


\section{Cell biology of the apical ectodermal ridge and ecto- derm}

The ectoderm of the developing limb bud only gives rise to the epidermis of the skin. But, as already outlined, this layer of cells including the specialised thickening, the apical ectodermal ridge, plays crucial roles during development producing secreted signalling molecules that act on underlying mesenchyme cells to control growth and patterning. The maintenance of the apical ridge and/or production of these signalling molecules in the ectoderm, in turn, are influenced by secreted signalling molecules produced by the mesenchyme. For a recent review of the apical ectodermal ridge see (Fernandez-Teran and Ros, 2008)

At early limb bud stages, the ectoderm consists of two cell layers, the inner layer of ectoderm cells being cuboidal and sitting on a basement membrane, the outer layer of ectoderm cells squamous and forming the periderm (Todt and Fallon, 1986; Fig. 2 ). The thickened apical ridge forms in early bud stages in developing chick limbs but later in mouse limb buds. In the ridge, the inner layer of cells are very elongated - this is why the ectoderm forms a thickened ridge - and also closely packed, and an outer layer of periderm cells is also present (Todt and Fallon, 1986). There are extensive gap junctions expressing connexin 43 between adjacent elongated apical ridge cells in both chick and mouse limb buds (Green et al., 1994; Meyer et al., 1997).

There have been no detailed studies of the patterns of cell proliferation in either apical ridge or ectoderm although it has been noted that there is marked cell death in the apical ridge (FernandezTeran et al., 2006). This raises the question of whether the apical ridge cell population turns over during development. However when the apical ridge from a quail limb bud was grafted in place of an apical ridge of a chick limb bud, the ridge at later stages still appeared to be composed of quail cells (Errick and Saunders, 1976). This finding also shows that non-ridge cells are not recruited to the ridge during development. In fact, recent Dil labelling experiments showed that during chick limb bud outgrowth cells in the anterior part of ridge is displaced proximally and appear to be assimilated into the non-ridge ectoderm (Vargesson et al., 1997). This behaviour contrasts with that of non-ridge ectoderm which is displaced distally in relation to the mesenchyme as the limb bud grows out (Amprino, 1977). It should be borne in mind that such displacements between apical ridge/ectoderm and underlying mesenchyme may affect the duration and timing of epithelial-mesenchymal interactions.

\section{Fate maps}

In order to understand how the limb develops and how genetics is linked with cell biology, it is essential to identify which regions of the early bud give rise to each of the limb structures. Several generations of fate mapping techniques have been applied to the developing chick wing (reviewed (Clarke and Tickle, 1999). The earliest fate maps were made by marking cells in the wing bud with vital dyes or by placing carbon particles in the limb bud (Saunders, 1948). More recently, chick-quail limb chimeras (Bowen et al., 1989) and cell marking using lipophilic dyes have been employed (Vargesson et al., 1997). The key findings that have consistently emerged are that the digits come from a rather small posteriordistal region of the early chick wing bud whereas the anterior-

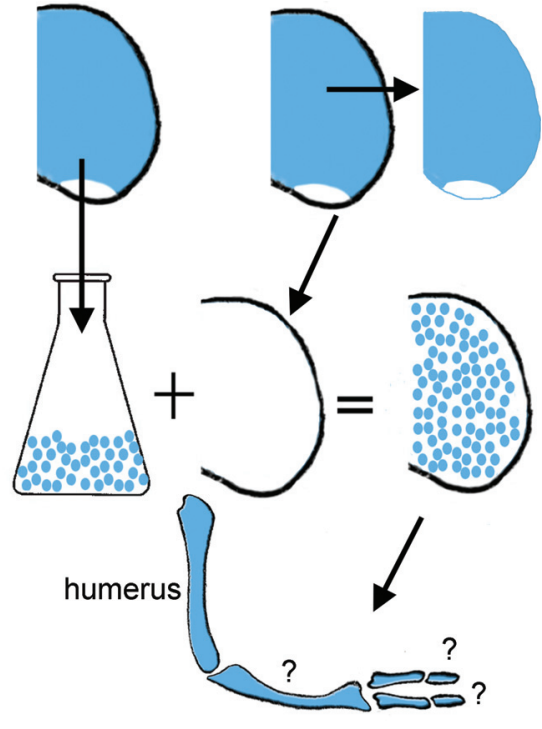

Fig. 3. Classical disggregration/reaggregation experiment in the chick wing. Disaggregated cells of a mesenchymal core from one wing bud are placed into the ectodermal jacket of another wing bud, which is then grafted to a host embryo to continue development. The recombinant wing bud resumes outgrowth resulting in a wing with a humerus, but unpatterned forearm elements and digits that are often reduced in number.

distal region does not give rise to distal structures. The lipophilic dye labelling studies also highlighted differences in behaviour between cells at different proximo-distal levels in the early limb bud; small groups of labelled cells in the proximal region of the bud remain proximal whereas cells at the tip of the early bud give rise to impressive stripes of cells along the proximo-distal axis with the stripes originating from medially positioned cells fanning out and curving anteriorly in the digit forming region (Vargesson et al., 1997).

The results of some cell lineage marking experiments in developing chick wings have been interpreted as showing that the different 'segments' of the limb along the proximo-distal axis, humerus, radius/ulna and the digits, constitute cell lineage restricted compartments (Dudley et al., 2002). This was used to support the idea that pattern along this axis is pre-specified in the early bud in discrete compartments, which are then amplified by growth before undergoing proximal-distal differentiation (see later). However, more recent fate maps (Pearse et al., 2007) and the results of further experiments directly addressing the relationship between cell fate and proximo-distal pattern failed to demonstrate the existence of proximo-distal compartments in the developing chick limb (Sato et al., 2007). For a recent update of the early specification model in which intercalary growth between distal and proximal regions is now proposed see (Mariani et al., 2008).

In contrast, dorso-ventral compartments have been found in both limb bud ectoderm and, more unexpectedly, limb bud mesoderm. Fate mapping experiments some years ago showed that the ectoderm of the limb-forming regions in chick embryos consists of dorsal and ventral cell lineage restricted compartments, and that apical ridge precursors are found fairly widely distributed throughout the ectoderm. These precursors then assemble at the 
dorso-ventral compartment boundary (Altabef et al., 1997). In the chick, apical ridge precursors for the wing bud are found in both dorsal and ventral ectoderm while for the leg bud most of the precursors originate in ventral ectoderm. Similar dorso-ventral ectodermal compartments have been demonstrated in mouse limb buds but ridge precursors were found only in ventral ectoderm (Kimmel et al., 2000), possibly due to differences in developmental timing. It is not clear in either mouse or chick how the ridge precursors within a coherent sheet of cells manage to come together to form the ridge. More recently, genetic fate mapping experiments in mouse embryos have shown that there are also dorso-ventral compartments in the mesenchyme of the limb bud (Arques et al., 2007). This is the first time that cell-lineage restricted compartments have been found in any mesenchymal tissue. Dorso-ventral mesenchymal compartments can also be demonstrated at limb bud stages in the chick (Pearse et al., 2007) although previous work had suggested that mesenchyme in limbforming regions is not compartmentalised (Altabef et al., 1997).

\section{Pattern regulation}

Fate maps only indicate which structure cells will eventually form, but not when their fate is determined. Several experimental approaches have tested whether limb buds can self-regulate i.e. accommodate either tissue deletions or additions. When undifferentiated tips of early and late buds were interchanged, limbs with either deleted or additional structures developed suggesting that the proximal-distal pattern is not regulative (Summerbell et al., 1973), but see (Kieny 1977) for experiments showing some evidence of regulation. In contrast, when the early chick limb bud was made either narrower or wider by cutting out a central strip of limb bud or by adding an extra strip, in both cases a normal patterned set of digits developed, showing that antero-posterior pattern in the early bud is highly regulative (Yallup and Hinchliffe 1983). More remarkably, it was discovered that when the cells of the mesenchymal core were disaggregated, the cells then mixed together, reaggregated, and encased in a limb ectodermal jacket, limb structures could still form (Fig. 3). Typically, such reaggregate limbs develop digit-like structures at the tip while more proximal structures are less recognisable (Zwilling, 1964; Ros et al., 1994; Hardy et al., 1995). The digit-like structures however do not have any recognisable pattern. Pattern can be rescued by grafting an intact polarizing region at one edge of the limb reaggregate (Ros et al., 1994). One particularly intriguing finding is that reaggregate limb buds made entirely from anterior limb mesenchyme form digits (Ros et al., 1994). However, if the posterior half of the early limb bud is cut away leaving just the anterior half still attached to the chick embryo, this anterior half only forms proximal structures (Niswander et al., 1994). This suggests that the anterior part of the limb bud is able to form digits but normally is inhibited from doing so and that the process of disaggregation/reaggregation in some way relieves this inhibition.

\section{Integration of patterning and growth}

A key issue in limb development is the relationship between patterning and growth. In the classical model for proximo-distal patterning, it was proposed that the precise pattern of elements along this axis is progressively specified as the limb grows out from the population of proliferative undifferentiated mesenchymal cells at the tip (Summerbell et al., 1973). This population of cells, the progress zone, is maintained in distal regions under the influence of apical-ridge signals, more recently, shown to include FGFs. As cells are sequentially displaced out of the progress zone, they no longer remain under the influence of ridge signalling and differentiate into the appropriate structure in a proximal to distal sequence. This model entirely involves growth because when the apical ridge is removed, outgrowth ceases and the limb becomes truncated (Saunders, 1948). Furthermore, in this model, growth is intimately involved in two processes - both specifying positional values along the proximo-distal axis but also generating the tissue from which the structures develop.

In contrast for the antero-posterior axis, the classical model is that a morphogen gradient, widely accepted to be based on Shh, specifies positional identity of cells in the early bud (reviewed, Tickle, 2006). This positional information then is 'remembered' by an uncharacterised memory mechanism and subsequently determines digit number and identity at later stages (Smith, 1979). It has long been recognized however that timing and growth also play an integral role in antero-posterior specification. When a polarizing region from one chick wing bud is grafted to the anterior margin of a second wing bud, a polarized set of extra digits is induced in the anterior part of the host bud in response to the graft and a mirror-image symmetrical pattern of digits is produced (Saunders and Gasseling, 1968; Fig. 4). It has been shown that the extent of digit duplication can be reduced by either attenuating the strength of the polarizing region or shortening the length of time that the graft is left in place (reviewed, Tickle, 2006). Furthermore, an early response to a graft of a polarizing region is stimulation of cell proliferation (Cooke and Summerbell, 1980). Indeed, when chick wing buds were $X$-irradiated after a polarizing region had been grafted into the anterior margin, the buds did not widen and anterior structures were lost thus demonstrating that growth appears to be required in order for the full range of positional values to be established (Smith and Wolpert, 1981; Fig. 4). However, these experiments have largely been overlooked but see (Towers et al., 2008) for a recent study that draws a similar conclusion. For other recent work on the role of growth in anteroposterior patterning see also (Zhu et al., 2008) and commentaries on these papers (Tabin and McMahon, 2008; Bastida and Ros, 2008; Francis-West and Hill, 2008).

Recently, the classical views of how proximo-distal and anteroposterior patterns are generated have been challenged. The new proposals are that proximo-distal pattern, as mentioned, may be pre-specified in the early bud (Dudley et al., 2002) (see Mariani et al., 2008 for updated model) and then expanded by FGF controlled growth, while antero-posterior pattern may be generated over time with cells taking on progressively posterior values the longer they are resident in the polarizing region (Harfe et al., 2004). It is important that these fundamental issues about how pattern is specified in the developing limb are resolved (Tabin and Wolpert, 2007; Towers and Tickle, 2009). Increasing numbers of genes are being discovered that are expressed in developing limbs and without a firm conceptual basis, it will be very difficult to begin to interpret their roles.

Another key issue is how the limb bud is shaped. All the mesenchymal cells in the early bud are dividing and yet the bud 


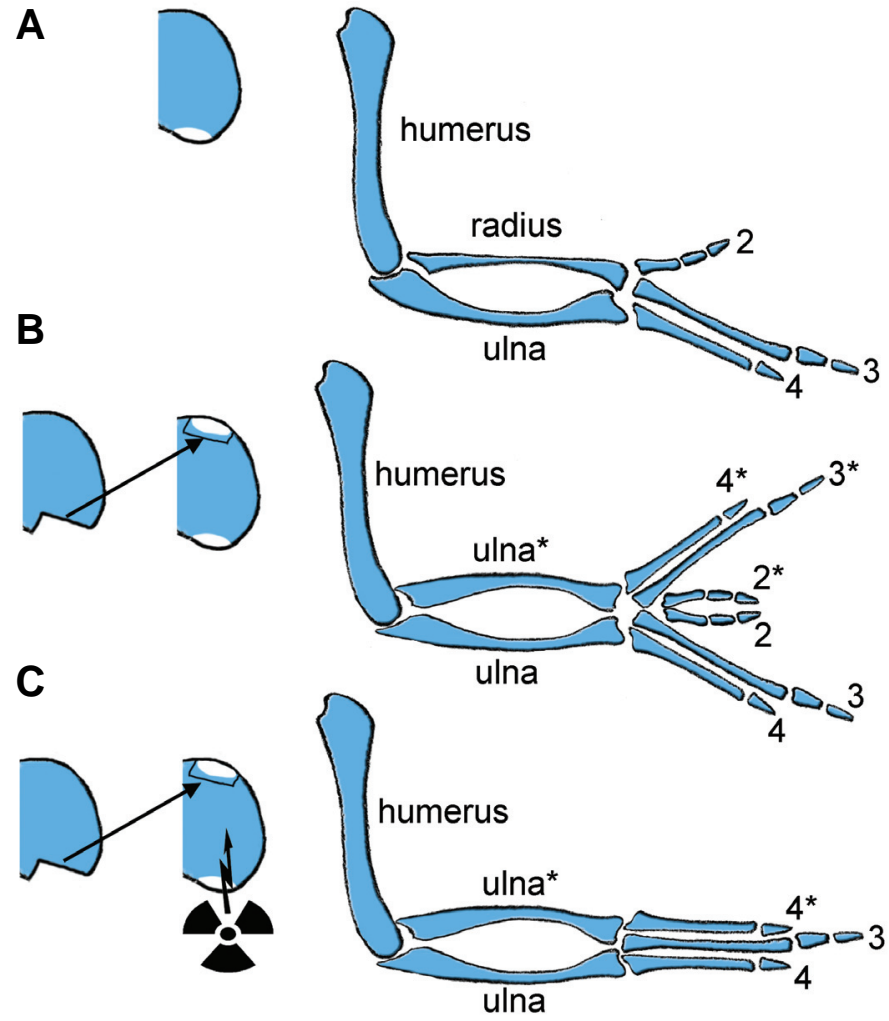

Fig. 4. Classical $X$-irradiation experiment in duplicated chick wings. (A) Normal chick wing bud and fully developed wing with digit pattern (234). (B) Classical polarizing region grafting experiments to the anterior margin of a host wing bud results in mirror-image digit duplications $(4322 * 3 * 4 *)$. (C) Same operation as in (B) but this time accompanied by $X$-irradiation which inhibits growth of the host wing bud; failure of anteroposterior expansion to accommodate the full range of opposing positional values is associated with missing anterior elements $(434 \%$ ). Asterisks denote duplicated elements.

grows out to form a dorso-ventrally flattened elongated structure. In addition, there are not any obvious differences in anterior/ posterior growth rates although it is clear that all the digits come from a small region at the posterior margin of the bud. One limitation of the analyses that have measured growth/cell cycle rates is that because mitosis is such a short phase of the cell cycle the number of mitotic cells is very low and it is difficult to obtain statistically significant data about whether cells in different regions of the limb are proliferating more than cells in other regions. These limitations should be overcome by investigating S- phase labelling because S-phase occupies a greater proportion of the cell cycle than mitosis but since these types of analyses are performed on sectioned material, this makes it very laborious to obtain meaningful data for the whole limb. Additionally, measuring one phase of the cell cycle is not necessarily informative about the total length, which could compensate for changes by increasing/decreasing the duration of another phase. These may be reasons why subtle differences in proliferation have not been detected antero-posteriorly even though fate maps clearly show that the posterior digit-forming part of early chick limb buds expands much more than the anterior part. Apoptosis could also contribute to the amount of limb tissue available to make distinct skeletal elements across the antero-posterior axis, although it is not clear whether localised cell death at the anterior, while contributing to anterior growth retardation, would be sufficient to explain this differential expansion observed in chick wing buds. Nevertheless, when cell death is dramatically reduced in the limb buds as, for example, in talpio ${ }^{\mathbb{P}}$ and talpid ${ }^{B}$ chick mutants, the buds are very broad and many digits form and later fuse (Ede and Kelly, 1964; Dvorak and Fallon, 1991).

The width of limb bud outgrowth is related to the length of the apical ridge. It has been well established that maintenance of the apical ridge is a consequence of polarizing region signalling and it was postulated that distal mesenchyme cells in response to polarizing region signals produce an apical ridge maintenance factor (Zwilling and Hansborough, 1956). The distribution of this factor would govern ridge length. There is now good evidence that this factor is the BMP antagonist Gremlin (Zuniga et al., 1999). However, Cooke and Summerbell observed enhanced cell cycle entry in mesenchyme within $5 \mathrm{hrs}$ after a polarizing region graft (Cooke and Summerbell, 1980) whereas maintenance of the apical ridge appears to occur later. These observations led to the suggestion that the polarizing region has a direct effect on mesenchyme cell proliferation independent of apical ridge maintenance (see also recent work by Towers et al., 2008).

It is unknown how directionality is imparted to limb bud outgrowth. It is tempting to speculate that FGF signalling by the ridge may be involved. FGFs act as chemoattractants and chemorepellents in the control of cell migration at gastrulation (Yang et al., 2002), and, in the limb, as already outlined, traces of marked cells extend towards localized sources of FGFs (Li and Muneoka, 1999). However, given that there is little gross movement by individual cells in early limb buds and most growth is mediated by proliferation, FGFs might instead have more subtle effects such as influencing the position that daughter cells adopt following mitosis. It has also been suggested that the apical ridge and/or ectoderm may fulfil a mechanical function and serve to constrain the expanding mesenchyme so preventing it from blowing up like a balloon. A number of observations are consistent with this but are not conclusive. Thus, for example when the apical ridge is removed and replaced by an FGF bead, growth can be rescued but the bud becomes very bulbous (Niswander et al., 1993).

\section{Future prospects}

This short review highlights the fact that despite intensive study of the developing limb our understanding is rather rudimentary. Thus, for example, there is still no general consensus about the fundamental ways in which pattern is specified. In addition, our knowledge of the genetic and molecular basis of the patterning process is fragmentary and most of the information about the cellular activities comes from work carried out many years ago. Much of the recent emphasis has been placed on identifying signalling pathways and transcription cascades and it has been difficult to couple the action of key patterning genes to the molecules that regulate the actual cellular processes that shape the limb and allow differentiation to take place. A few leads appear to be emerging such as the finding that Ephrins, known in other systems to be involved in maintaining cell lineage compartments, may be downstream of Hoxgenes (Salsi and Zappavigna, 2006) and that Connexin 40, a gap junction protein, may be a target of 
Tbx5 (Pizard et al., 2005). Since there has been a huge explosion in the knowledge of the genetic and molecular basis not only of embryonic development but also of cell behaviour, new insights might come from studying limb development from the bottom-up cellular perspective and integrating this with the top-down tissue patterning.

Opportunities are opening up that will allow a more systematic approach to limb development. For example, it will be possible to undertake genome-wide screening for all the genes expressed in the developing limb, and this will reveal new developmentally important genes and ultimately allow dissection of the gene networks that pattern the limb. This information could then be integrated into a firm conceptual framework of the underlying cellular processes that are taking place at a given space and time and help unravel the patterning and differentiation process. Finally, there are increasingly effective methods for testing the function of such genes and monitoring their outcomes. Transient transgenesis is also well-established in the chick limb and it is now possible to functionally inactivate genes specifically in the limbs of mouse embryos opening up a whole raft of experiments not previously possible due to early embryonic lethality (e.g. (Logan et al., 2002). In addition a whole range of new tools are becoming available for examining molecular, cellular and tissue limb anatomy, including Optical Projection Tomography (Sharpe et al., 2002) and micromagnetic resonance imaging ( $\mathrm{Li}$, et al., 2007). Thus, in the foreseeable future, much progress is expected in coupling genes and their products to the cellular processes that shape the developing limb and generate its anatomy.

\section{References}

ALLEN, F., TICKLE, C. and WARNER, A. (1990). The role of gap junctions in patterning of the chick limb bud. Development 108: 623-634.

ALTABEF, M., CLARKE, J.D. and TICKLE, C. (1997). Dorso-ventral ectodermal compartments and origin of apical ectodermal ridge in developing chick limb. Development 124: 4547-4556.

AMPRINO, R. (1977). Morphogenetic interrelationships between ectoderm and mesoderm in chick embryo limb development. In Vertebrate Limb and Somite Morphogenesis. (Ed. Ede, D.A., Hinchliffe, R. and Balls, M.J. ) Cambridge University Press, Cambridge.

ARAUJO, M., PIEDRA, M.E., HERRERA, M.T., ROS, M.A. and NIETO, M.A (1998). The expression and regulation of chick EphA7 suggests roles in limb patterning and innervation. Development 125: 4195-4204.

ARQUES, C.G., DOOHAN, R., SHARPE, J. and TORRES, M. (2007). Cell tracing reveals a dorsoventral lineage restriction plane in the mouse limb bud mesenchyme. Development 134: 3713-3722.

BARNA, M. and NISWANDER, L. (2007). Visualization of cartilage formation: insight into cellular properties of skeletal progenitors and chondrodysplasia syndromes. Dev Cel/12: 931-941.

BASTIDA, M.F., ROS, M.A. (2008). How do we get a perfect complement of digits? Curr Opin Genet Dev 18: 374-380.

BLASCHKE, R.J. and RAPPOLD, G. (2006). The pseudoautosomal regions, SHOX and disease. Curr Opin Genet Dev16: 233-239.

BOWEN, J., HINCHLIFFE, J.R., HORDER, T.J. and REEVE, A.M. (1989). The fate map of the chick forelimb-bud and its bearing on hypothesized developmental control mechanisms. Anat Embryol (Berl) 179: 269-283.

BROCKES, J.P. (1992). Introduction of a retinoid reporter gene into the urodele limb blastema. Proc Natl Acad Sci U S A 89: 11386-11390.

CAMERON, J.A. and FALLON, J.F. (1977). The absence of cell death during development of free digits in amphibians. Dev Bio/55: 331-338.

CHIANG, C., LITINGTUNG, Y., LEE, E., YOUNG, K.E., CORDEN, J.L., WESTPHAL,
H. and BEACHY, P.A. (1996). Cyclopia and defective axial patterning in mice lacking Sonic hedgehog gene function. Nature 383: 407-413.

CLARKE, J.D. and TICKLE, C. (1999). Fate maps old and new. Nat Cel/ Biol1: E103-E109.

COOKE, J. and SUMMERBELL, D. (1980). Cell cycle and experimental pattern duplication in the chick wing during embryonic development. Nature 287: 697 701.

DAHN, R.D. and FALLON, J.F. (2000). Interdigital regulation of digit identity and homeotic transformation by modulated BMP signaling. Science 289: 438-441.

DAWD, D.S. and HINCHLIFFE, J.R. (1971). Cell death in the «opaque patch» in the central mesenchyme of the developing chick limb: a cytological, cytochemical and electron microscopic analysis. J Embryol Exp Morpho/26: 401-424.

DUDLEY, A.T., ROS, M.A. and TABIN, C.J. (2002). A re-examination of proximodistal patterning during vertebrate limb development. Nature 418: 539-544.

DVORAK, L. and FALLON, J.F. (1991). Talpid2 mutant chick limb has anteroposterior polarity and altered patterns of programmed cell death. Anat Rec 231: 251-260.

ECHEVERRI, K. and TANAKA, E.M. (2005). Proximodistal patterning during limb regeneration. Dev Bio/279: 391-401.

EDE, D.A. (1977). The development of pre-cartilage condensations in limb bud mesencyme in vivo and in vivo. In Vertebrate Limb and Somite Morphogenesis (Ed. Ede, D.A., Hinchliffe, R. and Balls, M.J.). Cambridge University Press, Cambridge, pp. 161-180.

EDE, D.A. and KELLY, W.A. (1964). Developmental Abnormalities in the Trunk and Limbs of the Talpid3 Mutant of the Fowl. J Embryol Exp Morpho/12: 339-356.

ERRICK, J.E. and SAUNDERS, J.W., JR. (1976). Limb outgrowth in the chick embryo induced by dissociated and reaggregated cells of the apical ectodermal ridge. Dev Bio/50: 26-34.

FALLON, J.F., LOPEZ, A., ROS, M.A., SAVAGE, M.P., OLWIN, B.B. and SIMANDL, B.K. (1994). FGF-2: apical ectodermal ridge growth signal for chick limb development. Science 264: 104-107.

FERNANDEZ-TERAN, M.A., HINCHLIFFE, J.R. and ROS, M.A. (2006). Birth and death of cells in limb development: a mapping study. Dev Dyn235: 2521-2537.

FERNANDEZ-TERAN, M.A. and ROS, M.A. (2008). The Apical Ectodermal Ridge: morphological aspects and signaling pathways. Int. J. Dev. Biol. 52: 857-871.

FRANCIS-WEST, P and HILL, R. (2008). Uncoupling the role of sonic hedgehog in limb development: growth and specification. Sci Signal. 26: 34.

GREEN, C.R., BOWLES, L., CRAWLEY, A. and TICKLE, C. (1994). Expression of the connexin43 gap junctional protein in tissues at the tip of the chick limb bud is related to the epithelial-mesenchymal interactions that mediate morphogenesis. Dev Bio/161: 12-21.

GUMPEL-PINOT, M., EDE, D.A. and FLINT, O.P. (1984). Myogenic cell movement in the developing avian limb bud in presence and absence of the apical ectodermal ridge (AER). J Embryol Exp Morpho/80: 105-125.

HARDY, A., RICHARDSON, M.K., FRANCIS-WEST, P.H., RODRIGUEZ, C. IZPISUA-BELMONTE, J.C., DUPREZ, D. and WOLPERT, L. (1995). Gene expression, polarising activity and skeletal patterning in reaggregated hind limb mesenchyme. Development 121: 4329-4337.

HARFE, B.D., SCHERZ, P.J., NISSIM, S., TIAN, H., MCMAHON, A.P. and TABIN, C.J. (2004). Evidence for an expansion-based temporal Shh gradient in specifying vertebrate digit identities. Ce//118: 517-528.

KIENY, M. (1977). Proximo-distal pattern formation in vertebrate limb development In Vertebrate Limb and Somite Morphogenesis(Ed. Ede, D.A., Hinchliffe, R. and Balls, M.J.). Cambridge UniversityPress, Cambridge.

KIMMEL, R.A., TURNBULL, D.H., BLANQUET, V., WURST, W., LOOMIS, C.A. and JOYNER, A.L. (2000). Two lineage boundaries coordinate vertebrate apical ectodermal ridge formation. Genes Dev 14: 1377-1389.

KOSTAKOPOULOU, K., VARGESSON, N., CLARKE, J.D., BRICKELL, P.M. and TICKLE, C. (1997). Local origin of cells in FGF-4 - induced outgrowth of amputated chick wing bud stumps. Int J Dev Bio/41: 747-750.

LI, S. and MUNEOKA, K. (1999). Cell migration and chick limb development: chemotactic action of FGF-4 and the AER. Dev Bio/211: 335-347.

LI, X., LIU, J, DAVEY, M, DUCE, S, JABERI, N, LIU, G, DAVIDSON, G, TENENT, S, MAHOOD, R, BROWN, P, CUNNINGHAM, C, BAIN, A, BEATTIE, K, MCDONALD, L, SCHMIDT, K, TOWERS, M, TICKLE, C AND CHUDEK, S. 
(2007). Micro-magnetic resonance imaging of avian embryos. J. Anatomy211: 798-809.

LOGAN, M., MARTIN, J.F., NAGY, A., LOBE, C., OLSON, E.N. and TABIN, C.J. (2002). Expression of Cre Recombinase in the developing mouse limb bud driven by a Prxl enhancer. Genesis 33: 77-80.

MADEN, M. (1982). Vitamin A and pattern formation in the regenerating limb. Nature 295: 672-675.

MAKARENKOVA, H., BECKER, D.L., TICKLE, C. and WARNER, A.E. (1997). Fibroblast growth factor 4 directs gap junction expression in the mesenchyme of the vertebrate limb Bud. J Cel/ Bio/138: 1125-1137.

MARIANI, F.V., AHN, C.P., MARTIN, G.R. (2008). Genetic evidence that FGFs have an instructive role in limb proximal-distal patterning. Nature 453: 401-5.

MERCADER, N., LEONARDO, E., PIEDRA, M.E., MARTINEZ, A.C., ROS, M.A. and TORRES, M. (2000). Opposing RA and FGF signals control proximodistal vertebrate limb development through regulation of Meis genes. Development 127: 3961-3970.

MEYER, R.A., COHEN, M.F., RECALDE, S., ZAKANY, J., BELL, S.M., SCOTT, W.J., JR. and LO, C.W. (1997). Developmental regulation and asymmetric expression of the gene encoding $\mathrm{C} \times 43$ gap junctions in the mouse limb bud. Dev Genet 21: 290-300

NARDI, J.B. and STOCUM, D. L. (1984). Surface properties of regenerating limb cells: Evidence for gradation along the proximodistal axis. Differentiation25:2731

NISSIM, S., ALLARD, P., BANDYOPADHYAY, A., HARFE, B.D. and TABIN, C.J. (2007). Characterization of a novel ectodermal signaling center regulating $\mathrm{Tbx} 2$ and Shh in the vertebrate limb. Dev Bio/304: 9-21.

NISWANDER, L. (2003). Pattern formation: old models out on a limb. Nat Rev Genet 4: 133-143.

NISWANDER, L., JEFFREY, S., MARTIN, G.R. and TICKLE, C. (1994). A positive feedback loop coordinates growth and patterning in the vertebrate limb. Nature 371: 609-612.

NISWANDER, L., TICKLE, C., VOGEL, A., BOOTH, I. and MARTIN, G.R. (1993). FGF-4 replaces the apical ectodermal ridge and directs outgrowth and patterning of the limb. Cel/75: 579-587.

PEARSE, R.V., 2ND, SCHERZ, P.J., CAMPBELL, J.K. and TABIN, C.J. (2007). A cellular lineage analysis of the chick limb bud. Dev Bio/310: 388-400.

PIZARD, A., BURGON, P.G., PAUL, D.L., BRUNEAU, B.G., SEIDMAN, C.E. and SEIDMAN, J.G. (2005). Connexin 40, a target of transcription factor Tbx5, patterns wrist, digits, and sternum. Mo/ Cel/ Bio/25: 5073-5083.

ROS, M.A., DAHN, R.D., FERNANDEZ-TERAN, M., RASHKA, K., CARUCCIO, N.C., HASSO, S.M., BITGOOD, J.J., LANCMAN, J.J. and FALLON, J.F. (2003). The chick oligozeugodactyly (ozd) mutant lacks sonic hedgehog function in the limb. Development 130: 527-537.

ROS, M.A., LYONS, G.E., MACKEM, S. and FALLON, J.F. (1994). Recombinant limbs as a model to study homeobox gene regulation during limb development. Dev Biol 166: 59-72.

SALSI, V. and ZAPPAVIGNA, V. (2006). Hoxd13 and Hoxa13 directly control the expression of the EphA7 Ephrin tyrosine kinase receptor in developing limbs. $J$ Biol Chem 281: 1992-1999.

SATO, K., KOIZUMI, Y., TAKAHASHI, M., KUROIWA, A. and TAMURA, K. (2007). Specification of cell fate along the proximal-distal axis in the developing chick limb bud. Development 134: 1397-1406.

SAUNDERS, J.W. and GASSELING, M.T. (1968). Ectodermal-mesenchymal interactions in the origin of limb symmetry. In mesenchymal-epithelial interactions (ed. R. Fleichmeyer and R. E. Billingham), illiams and Wilkins, Baltimore, pp. 78-97.

SAUNDERS, J.W., JR. (1948). The proximo-distal sequence of origin of the parts of the chick wing and the role of the ectoderm.. J Exp Zoo/282: 628-668.

SAUNDERS, J.W., JR. and GASSELING, M.T. (1962). Cellular death in morphogenesis of the avian wing. Dev Bio/5: 147-178.

SHARPE, J., AHLGREN, U., PERRY, P., HILL, B., ROSS, A., HECKSHERSORENSEN, J., BALDOCK, R. and DAVIDSON, D. (2002). Optical projection tomography as a tool for 3D microscopy and gene expression studies. Science 296: 541-545.
SMITH, J.C. (1979). Evidence for a positional memory in the development of the chick wing bud. J Embryol Exp Morpho/52: 105-113.

SMITH, J.C. and WOLPERT, L. (1981). Pattern formation along the anteroposterior axis of the chick wing: the increase in width following a polarizing region graft and the effect of X-irradiation. J Embryo/ Exp Morpho/63: 127-144.

SUMMERBELL, D., LEWIS, J.H. and WOLPERT, L. (1973). Positional information in chick limb morphogenesis. Nature 244: 492-496.

SUMMERBELL, D. and WOLPERT, L. (1972). Cell density and cell division in the early morphogenesis of the chick wing. Nat New Bio/239: 24-26.

TABIN, C. and WOLPERT, L. (2007). Rethinking the proximodistal axis of the vertebrate limb in the molecular era. Genes Dev 21: 1433-1442.

TABIN, C.J, MCMAHON, A.P. (2008). Developmental biology. Grasping limb patterning. Science 321: 350-352

TAMURA, K., YOKOUCHI, Y., KUROIWA, A. and IDE, H. (1997). Retinoic acid changes the proximodistal developmental competence and affinity of distal cells in the developing chick limb bud. Dev Bio/188: 224-234.

TICKLE, C. (2006). Making digit patterns in the vertebrate limb. Nature Reviews Molecular Biology 7: 45-53.

TICKLE, C., ALBERTS, B., WOLPERT, L. and LEE, J. (1982). Local application of retinoic acid to the limb bond mimics the action of the polarizing region. Nature 296: $564-566$

TICKLE, C., GOODMAN, M. and WOLPERT, L. (1978). Cell contacts and sorting out in vivo: the behaviour of some embryonic tissues implanted into the developing chick wing. J Embryol Exp Morpho/48: 225-237.

TODT, W.L. and FALLON, J.F. (1986). Development of the apical ectodermal ridge in the chick leg bud and a comparison with the wing bud. Anat Rec215:288-304

TOOLE, B.P., MUNAIM, S.I., WELLES, S. and KNUDSON, C.B. (1989). Hyaluronate-cell interactions and growth factor regulation of hyaluronate synthesis during limb development. Ciba Found Symp 143: 138-45.

TOWERS, M., MAHOOD, R., YIN, Y., TICKLE C. (2008). Integration of growth and specification in chick wing digit-patterning. Nature 452: 882-6.

TOWERS, M and TICKLE, C. (2009). Growing models of vertebrate limb development. Development 136: 179-190.

TRELSTAD, R.L. (1977). Mesenchymal cell polarity and morphogenesis of chick cartilage. Dev Bio/59: 153-163.

VARGESSON, N., CLARKE, J.D., VINCENT, K., COLES, C., WOLPERT, L. and TICKLE, C. (1997). Cell fate in the chick limb bud and relationship to gene expression. Development 124: 1909-1918.

VARGESSON, N., PATEL, K., LEWIS, J. and TICKLE, C. (1998). Expression patterns of Notch1, Serrate1, Serrate2 and Delta1 in tissues of the developing chick limb. Mech Dev 77: 197-199.

WADA, N. and IDE, H. (1994). Sorting out of limb bud cells in monolayer culture. Int J Dev Bio/38: 351-356.

YALLUP, B.L., AND J.R. HINCHLIFFE. (1983). Regulation along the anteroposterior axis of the chick wing bud. In Limb Development and Regeneration, Part $A$. (Ed. J.F. Fallon and A.I. Caplan), Alan R. Liss, Inc., New York, pp. 131-140.

YANG, X., DORMANN, D., MUNSTERBERG, A.E. and WEIJER, C.J. (2002). Cell movement patterns during gastrulation in the chick are controlled by positive and negative chemotaxis mediated by FGF4 and FGF8. Dev Ce// 3: 425-437.

ZHU, J., NAKAMURA, E., NGUYEN, M.T., BAO, X., AKIYAMA, H. and MACKEM. S. (2008). Uncoupling Sonic hedgehog control of pattern and expansion of the developing limb bud. Dev Cell. 14: 624-632.

ZUNIGA, A., HARAMIS, A.P., MCMAHON, A.P. and ZELLER, R. (1999). Signa relay by BMP antagonism controls the $\mathrm{SHH} / \mathrm{FGF} 4$ feedback loop in vertebrate limb buds. Nature 401: 598-602

ZUZARTE-LUIS, V. and HURLE, J.M. (2002). Programmed cell death in the developing limb. Int J Dev Bio/46: 871-876.

ZWILLING, E. (1964). Development of Fragmented and of Dissociated Limb Bud Mesoderm. Dev Bio/89: 20-37.

ZWILLING, E. and HANSBOROUGH, L. (1956). Interactions between limb bud ectoderm and mesoderm in the chick embryo. III. Experiments with polydactylous limbs. J Exp Zoo 132: 219-239. 


\section{Further Related Reading, published previously in the Int. J. Dev. Biol.}

See our Special Issue Pattern Formation edited by Chung-Ming Chuong and Michael K. Richardson at: http://www.ijdb.ehu.es/web/contents.php?vol=53\&issue=5-6

See our Special Issue Limb Development, edited by Juan Hurlé and Juan-Carlos Izpisua-Belmonte at: http://www.ijdb.ehu.es/web/contents.php?vol=46\&issue $=7$

The expression of Fat-1 cadherin during chick limb development Terence G. Smith, Nick Van Hateren, Cheryll Tickle and Stuart A. Wilson Int. J. Dev. Biol. (2007) 51: 173-176

Human limb malformations; an approach to the molecular basis of development. Karl-Heinz Grzeschik Int. J. Dev. Biol. (2002) 46: 983-991

Cell adhesiveness and affinity for limb pattern formation. Hiroshi Yajima, Kenji Hara, Hiroyuki Ide and Koji Tamura Int. J. Dev. Biol. (2002) 46: 897-904

Interplay between the molecular signals that control vertebrate limb development. Lee Niswander Int. J. Dev. Biol. (2002) 46: 877-881
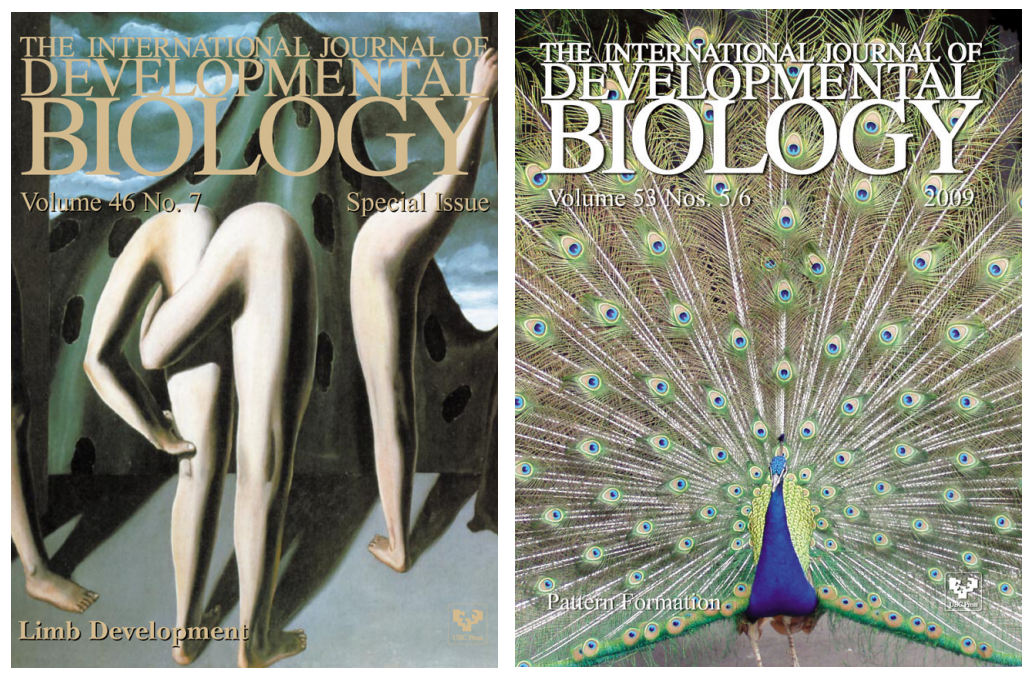

5 yr ISI Impact Factor $(2008)=3.271$ 